\title{
Diseño de los implantes dentales: Estado actual
}

\author{
MARTÍNEZ-GONZÁLEZ JM \\ CANO SÁNCHEZ J \\ CAMPO TRAPERO J \\ MARTÍNEZ-GONZÁLEZ MJS \\ GARCÍA-SABÁN F
}

\begin{abstract}
Martínez-González JM, Cano Sánchez J, Campo Trapero J, MartínezGonzález MJS, García-Sabán F. Diseño de los implantes dentales: Estado actual. Av Periodon Implantol. 2002; 14, 3: 129-136.
\end{abstract}

\begin{abstract}
RESUMEN
El diseño de los implantes dentales se están modificando continuamente debido a razones clínico-científicas y comerciales. Se realiza un revisión de la literatura en relación a las implicaciones clínicas y biológicas de las variaciones en macrogeometría y su influencia en la interfase con la mucosa y el hueso.

Los resultados descritos en la literatura muestran que los nuevos diseños de implantes mejoran la estabilidad primaria en huesos de baja densidad y distribuyen mejor las cargas biomecánicas. Existen diseños que favorecen la colocación de implantes en defectos de la anatomía alveolar y alveólos postextracción. Los resultados experimentales y clínicos evidencian un beneficio para diseños que eliminan el cuello pulido, con cuerpo cónico, con ápice autorroscante, a base de dobles o triples espiras y perfiles de rosca redondeadas.
\end{abstract}

\section{PALABRAS CLAVE}

Diseño, macrogeometría, implante.

\section{INTRODUCCIÓN}

El diseño o macrogeometría de los implantes dentales ha sido modificado continuamente en los últimos años con el objetivo de adaptarse y mejorar nuevos procedimientos clínicos (carga inmediata o precoz, hueso de mala densidad) y por un interés comercial de encontrar una imagen de marca diferenciadora.

En relación al diseño de los implantes intraóseos, se han ido desechando una serie de macrogeometrías como los implantes transmandibulares por su dificultad técnica y complicaciones postoperatorias, los implantes impactados por su transmisión biomecánica desfavorable al hueso (1) y los implantes laminares también por su mala distribución biomecánica (2).

Actualmente, es una opinión generalizada que los mejores resultados clínicos y de transmisión biome- cánica se consiguen con una macrogeometría roscada en forma de raiz dental (3). El reto se encuentra ahora en buscar cuál es el diseño que consigue unas mejores propiedades biológicas y biomecánicas, modificando ese diseño inicial roscado.(Figura 1) Mención aparte, requiere un diseño de implante en forma de cono truncado con superficie porosa sinterizada (Endopore, Innova, Toronto, Canada), que si bien se coloca mediante un procedimiento quirúrgico impactado, parece que la distribución biomecánica no es tan desfavorable, y los resultados clínicos a medio plazo así lo avalan (4)

El objetivo de este artículo es realizar una revisión de la literatura en relación a la situación actual de los diseños implantarios, atendiendo a la influencia de las diferentes modificaciones en la biología ósea y de los tejidos blandos adyacentes al implante y las repercusiones clínicas que conllevan. La macrogeometría del

* Departamento de Cirugía y Medicina Bucofacial. Facultad de Odontología. UCM. Madrid. 


\section{AVANCES}

Volumen 14 - N $\mathrm{N}^{\mathrm{O}} 3$ - Octubre 2002

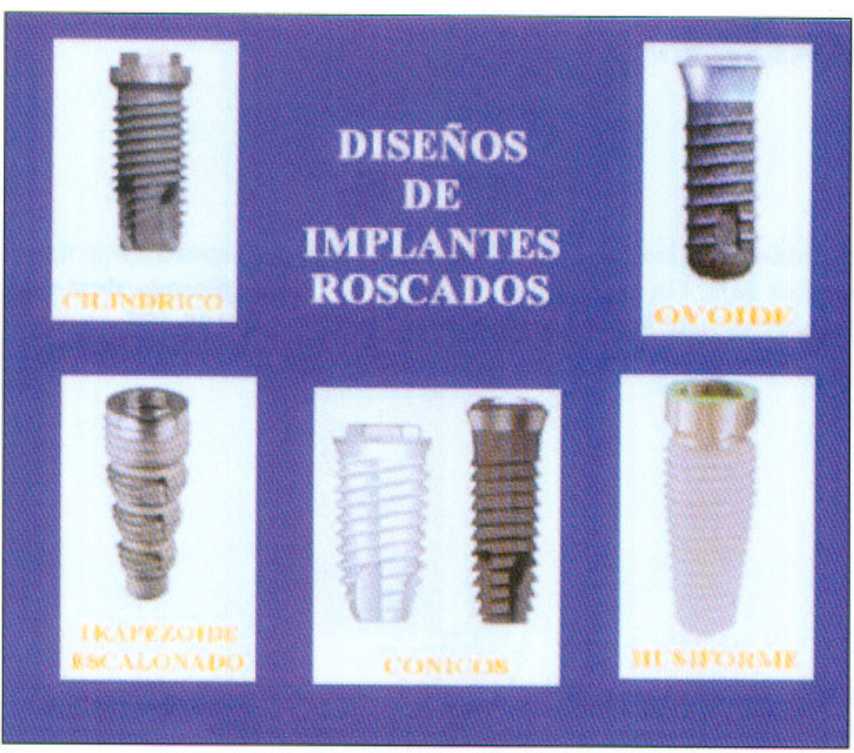

Fig. 1: Diseños de implantes roscados.

implante va a influir directamente en tres aspectos clínico-biológicos:

1- Aumento de la estabilidad primaria y del torque de inserción.

2- Adaptación a defectos anatómicos y alveolos postextracción.

3- Mantenimiento o reabsorción de la cresta ósea marginal.

\section{ESTABILIDAD PRIMARIA Y TORQUE DE INSERCIÓN}

La estabilidad primaria se define como la resistencia y rigidez de la unión hueso-implante antes de producirse la osteointegración. Se considera una necesidad mecánica para evitar el micromovimiento inicial en la interfase hueso-implante. Va a depender de tres factores: el diseño del implante, el procedimiento quirúrgico utilizado y de la densidad y dureza del hueso. La estabilidad secundaria es la suma de la estabilidad primaria y la estabilidad conseguida por la aposición ósea durante la cicatrización perimplantaria. Un implante que no tenga una buena estabilidad inicial puede conseguir la oseointegración si el tiempo de cicatrización es suficiente, mientras que una buena estabilidad primaria reduciría el tiempo de cicatrización. De hecho, implantes colocados en hueso de baja densidad consiguen una estabilidad secundaria similar a los colocados en hueso de mayor densidad cuando el tiempo de cicatrización es elevado (8 meses) (5). La estabilidad primaria va a estar directamente relacionada con el torque de inserción o fuerza de roscado (6).
En el hueso de baja densidad o tipo IV las tasas de supervivencia son menores (entre $50-94 \%$ según los autores) en comparación a los otros tipos de hueso (7). En este tipo de hueso se están buscando diseños que mejoren la compactación del mismo y eliminen la mínima cantidad posible. Actualmente, la mayoría de los sistemas tienen un diseño de ápice autorroscante que evita el antiguo aterrajado que eliminaba más hueso de lo deseable.

Para aumentar la estabilidad se han diseñado geometrías que presentan cierta conicidad en el 1/3 cervical - el cuello del implante para compactar el hueso y evitar el uso de avellanados corticales que eliminan hueso.(P.Ej ST,Astra-Tech; Mk IV, Nobelbiocare; TSA, Impladent). Este cuerpo cónico que es una ventaja en los huesos de mala calidad no es de elección en huesos muy compactos ya que se ejercería una presión elevada que podría generar sobrecarga ,isquemia y osteolisis (8). O'Sullivan y cols (9), realizaron un estudio in vitro en hueso humano de cadáver para valorar un diseño cónico con doble espira (Mk IV, Nobelbiocare) con dos diseños cilíndricos de paredes rectas (Osseotite, 3i; TiOblast, Astra-Tech). Se observaron datos significativamente mayores tanto en el torque de inserción como en la medición de frecuencia de resonancia, para el implante cónico en comparación a los dos implantes cilíndricos.(18,6, 8, Ncm para la inserción del torque; $7,9,6,3,6,2 \mathrm{KHz}$ para el análisis de frecuencia de resonancia respectivamente).

El diseño cónico también ha permitido aumentar la estabilidad primaria para proceder a aplicar protocolos de carga precoz o inmediata. Payne y cols., realizaron un seguimiento de 1 año en 10 pacientes a los que se colocaron 2 implantes con diseño cónico en sector anterior mandibular (Implantes autorroscantes con cuello cónico transmucosos, Nobelbiocare) cargados inmediatamente de manera progresiva y rehabilitados con sobredentaduras retenidas por bolas a las 2 semanas. El índice de éxito fue del $100 \%$ observándose pérdidas de cresta ósea similares a las encontradas en los procedimientos de carga convencionales (10).

En el caso de no disponer de implantes cónicos en hueso de baja densidad, también se puede cambiar la secuencia de fresado utilizando diámetro de fresado mas pequeño al de una secuencia normal (6).

También se han modificado el tamaño del perfil de rosca a lo largo del implante con el fin de que la fijación no sea igual de agresiva en toda su longitud sino que actúe como un osteotomo condensando el hueso Hay diseños en el que el perfil de rosca es más pequeño en la zona cervical (P.Ej ST, Astra-Tech) y otros en el que es más pequeño en el ápice (P.Ej Replace, Nobelbiocare). 
Otra modificación son los diseños con doble o triple espira que hace que aumente la distancia entre el paso de rosca que se ancla en el hueso con lo cual se elimina menos hueso, también reduce el tiempo de inserción de la fijación, reduce el calor generado, y aumenta el torque de inserción en huesos de baja densidad.

\section{ADAPTACIÓN A DEFECTOS ANATÓIMICOSY ALVEOLOS POSTEXTRACCIÓN}

Se han desarrollado geometrías para adaptarse a los alveolos postextracción de manera más fisiológica (P.Ej Frialit -2 , Friadent) y a los defectos anatómicos normales $u$ originados tras un proceso de atrofia. (P.Ej Replace, Nobelbiocare).

Se ha demostrado que el alveolo postextracción puede sufrir reabsorciones verticales de 3-4 $\mathrm{mm}$ en los 6 meses posteriores a la exodoncia si no se realizan técnicas de regeneración. Con el fin de realizar implantación inmediata se necesitan geometrías de implante que se adapten adecuadamente al alveolo y así, el espacio con el hueso adyacente sea los menor posible lo cual va a favorecer la osteogénesis de contacto y la disminución del tiempo de curación ósea perimplantaria. La perfecta adaptación del implante al alveolo va a evitar la necesidad de utilización de materiales de injerto o de colocación de membranas (se colocan cuando ese gap es > de $1 \mathrm{~mm}$ (11), lo que repercute en una técnica quirúrgica sin necesidad de elevar colgajos mucoperiósticos. En esta técnica de implantación inmediata se puede colocar un pilar de cicatrización atornillado al que se le rebasa una corona provisional que se mantendrá inmediatamente en anoclusión o no, según las características óseas (12).

En el caso de alveólos afectados con una infección crónica periapical, no es conveniente realizar la implantación inmediata, siendo deseable diferir la intervención durante tres o cuatro semanas después de la exodoncia para controlar el proceso infeccioso. Se debe favorecer un cierre primario de los tejidos blandos realizando, si es necesario, algún colgajo de translocación para cubrir el alveolo y reducir la reabsorción ósea. Schultes y Gaggl, (13) realizan un estudio en mandíbula de perros donde comparan el hueso neoformado y el tejido blando alrededor de implantes inmediatos e implantes tardíos. Encontraron mayor porcentaje hueso-implante en los implantes tardíos que en los casos inmediatos (aunque no significativo), achacándolo a el mayor crecimiento apical del tejido conectivo en los implantes inmediatos. Los autores consideran que el gap de la zona coronal en los implantes inmediatos en caso de no ser cubierto con métodos de barrera, va a originar una inserción larga del tejido conectivo con una reabsorción ósea aproximada de $1 \mathrm{~mm}$. Se considera que es necesario un espesor mínimo de hueso de $1,5 \mathrm{~mm}$ alrededor del implante para que se produzca una correcta regeneración ósea perimplantaria. La utilización de diseños husiformes o cónicos, permiten la permanencia de este espesor óseo y evitan las fenestraciones y dehiscencias (14). Espesores menores de $1,5 \mathrm{~mm}$ de hueso en la zona vestibular del implante va a favorecer la reabsorción ósea en esa zona entre la primera y la segunda fase en los implantes sumergidos. También la distancia interimplante va a influir para aumentar la reabsorción de tal forma que en situaciones en la que ésta es menor de $3 \mathrm{~mm}$, la reabsorción es significativamente mayor debido a la búsqueda del sellado biológico. Cuando el espacio entre implantes es menor a $3 \mathrm{~mm}$ se produciría una reabsorción horizontal de la cresta que influiría en la regeneración de la papila interimplante, con importantes repercusiones estéticas (15).

\section{MANTENIMIENTO O REABSORCIÓN DE LA CRESTA ÓSEA MARGINAL}

En los criterios de éxito se ha establecido que en el primer año después de colocar el implante es normal un pérdida en la altura de la cresta marginal de 11,5mm (16). Sin embargo, podemos preguntarnos por qué se produce este fenómeno, observándose incluso en algunos casos pérdidas de $3 \mathrm{~mm}$ antes de someter a los implantes a carga, y lo que es más importante por qué hay que asumir como normal esta pérdida. Parece que influirían diferentes factores y se han establecido varias hipótesis:

\section{1-BÚSQUEDA DEL SELLADO BIOLÓGICO}

Más que una hipóteis es un hecho probado que en algunos casos explicaría como razón única la pérdida de la cresta ósea marginal. En el caso de existir un espesor de mucosa $<3 \mathrm{~mm}$ el tejido blando reabsorbería el hueso hasta conseguir ese espesor y así desarrollar el sellado biológico (Figura 2). Cuando existe este espesor fino de mucosa, se va a producir siempre una reabsorción ósea independientemente del diseño del implante. Para anticiparse a este problema se pueden aplicar dos alternativas:

- Utilizar diseños con cuellos pulidos, esperando que el tejido blando se adapte a esa zona pulida, cuando se produzca la reabsorción. No es recomendable por la pérdida de anclaje óseo. 


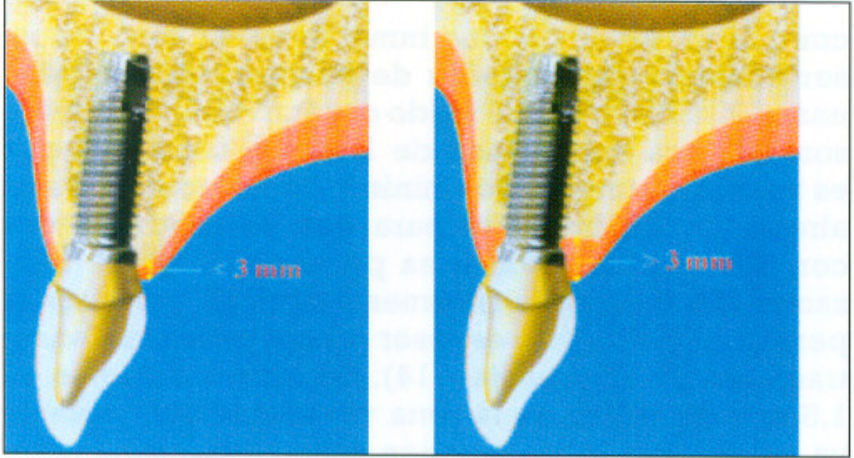

Fig. 2: Reabsorción crestal en la búsqueda del sellado biológico.

- Modificar el protocolo quirúrgico sumergiendo un poco más el implante, de tal manera que al aumentar el espesor de mucosa el nivel de cresta ósea se quede a nivel de la plataforma.

Este fenómeno, también ocurre cuando los implantes sumergidos exponen su tornillo de cierre en alguno de sus bordes al medio oral de manera prematura antes de realizar la segunda fase, ya sea por dehiscencia de la sutura o porque la encía es muy fina. Si la exposición del tornillo es parcial parece que existiría mayor contaminación bacteriana, por lo que habría que exponerlo por completo .En estos casos, siempre que exista una buena estabilidad primaria del implante es mejor colocar unos tornillos de cicatrización cortos lo antes posible y resuturar los tejidos adaptados a ese pilar, evitando así la reabsorción crestal y favoreciendo una buena higiene (17).

Con el objetivo de facilitar este sellado biológico se está estudiando cuál debe ser la rugosidad y el espesor ideal de los pilares o los cuellos transmucosos de los implantes. En relación a la rugosidad se ha observado que los pilares rugosos almacenan 25 veces más bacterias que los pilares de superficies lisas. Se ha observado in vitro que el grado crítico de rugosidad de superficie parece que está en Ra 0,2 $\mu \mathrm{m}$, por encima del cual hay un aumento significativo en la acumulación de placa (18).

Se considera que la zona donde va a ir insertado el epitelio debería ser electropulido (2 $\mathrm{mm})$, por la mayor adhesión de los hemidesmosomas de las células epiteliales a las zonas pulidas; mientras que la zona donde se une el conectivo debería ser parcialmente rugoso (1-1,5mm) por la mejor proliferación y diferenciación fibroblástica (19). Tanto las células epiteliales como los fibroblastos se unen a las superficies a traves de integrinas.

Con el fín de que las fibras colágenas se adapten mejor a los cuellos transmucosos, se está investigando cuál es la rugosidad ideal en esta zona sin llegar a una rugosidad tan importante como para favorecer la contaminación bacteriana. De esta forma se están evitando los diseños totalmente pulidos de estas zonas de unión al conjuntivo, y se está buscando una ligera rugosidad ya sea con mecanizados o con grabado ácido. Se han desarrollado diseños híbridos de superficies en la zona ósea con el fin de disminuir la reabsorción ósea y mejorar el mantenimiento de los tejidos blandos en el caso de que la superficie rugosa entre en contacto con la mucosa. De esta manera hay sistemas que tienen superficies híbridas (P.Ej Dual Transition, Sulzer-Dental) o progresivas (P.Ej TiUnite, Nobelbiocare) con menor rugosidad en la zona coronal del implante que en la apical, por si se produjera una comunicación con el medio oral.

\section{2-INVASIÓN BACTERIANA DEL MICROGAP}

Se ha establecido la hipótesis de que la interfase pilar-implante y su posible invasión bacteriana podría ser la responsable de la reabsorción de la cresta ósea, tras producción de infiltrado inflamatorio en la mucosa a nivel de esa interfase. Hay que tener en cuenta que los implantes sumergidos (dos fases) tienen dos interfases (pilar-implante y pilar-prótesis) mientras que los no sumergidos (una fase) tienen solo una interfase (implante-prótesis). Hermann y cols (20) observaron en un estudio experimental en implantes sin cargar, que los implantes sumergidos presentaban una pérdida ósea de $2 \mathrm{~mm}$ apicalmente a la interfase implante-pilar, mientras que esto no se producía en implantes no sumergidos. Los autores también establecen como posibles causantes de la reabsorción los micromovimientos del pilar que se une a los tejidos blandos y el déficit de aporte sanguíneo cuando se realiza la segunda cirugía para conectar los pilares. Por otro lado los rangos de anchura de esta interfase (pilar-implante) varían según los sistemas desde 5 a $49 \mu \mathrm{m}$, teniendo en cuenta que esta interfase pude aumentarse por el aflojamiento de los tornillos del sistema. Debido a que el diámetro promedio de una bacteria es de $2 \mu \mathrm{m}$, es fácil pensar la colonización de esta zona directamente o también a través de las estructuras internas del sistema (21).

Hermann y cols (22), realizaron un estudio experimental en mandíbula de perro con un periodo de curación de 6 meses valorando la reabsorción crestal con microimplantes colocados con técnica sumergida y no sumergida, de 1 ó 2 piezas. Refirieron mayor perimplantitis para los implantes con 2 piezas y observaron en todos los casos reabsorción de la cresta hasta llegar a la zona rugosa del implante, menos en los implantes no sumergidos en los que la zona rugosa se colocó de manera paracrestal. Los autores relacionan la reabsorción a la existencia de la interfase pilar-implante, pero esto no debería ser confirma- 
do de modo categórico ya que en los diseños de implante estudiados no existía un sistema sumergido con la zona rugosa hasta la zona paracrestal (sin cuello pulido) que sería el sistema a comparar. Por otro lado, también se observó reabsorción de hueso hasta la zona rugosa en sistemas donde no existía el gap. En cualquier caso, este fenómeno no ha sido investigado en humanos y no está claro el papel que cumple esta interfase en la reabsorción crestal. Por otro lado, hay estudios clínicos que demuestran radiológicamente una pérdida ósea media en el primer año de tratamiento con implantes no sumergidos de 0,78 mm (23) que rebatiría la hipótesis de la colonización bacteriana de la unión implante-pilar como justificante único de la reabsorción crestal.

Hay que tener en cuenta, que los implantes no sumergidos presentan una dificultad para obtener buenos resultados estéticos en el sector anterior con los perfiles de emergencia más adecuados, debido a que es difícil predecir al nivel que van a quedar los tejidos blandos después de la cicatrización. Esto se intenta solventar con el diseño de cuellos transmucosos más pequeños (1,8 mm). Además puede existir una carga prematura del implante en el caso de utilizar prótesis removible en el periodo de cicatrización cuando la estabilidad primaria no ha sido muy adecuada. Se ha demostrado también experimentalmente que no existen diferencias de los tejidos blandos perimplantarios entre los sistemas no sumergidos y los sumergidos (24).

A favor de esta teoría existen evidencias en donde sistemas que utilizan una conexión interna cónica, existiría una reducción del microgap con menor colonización bacteriana, observándose reabsorciones de la cresta ósea en el primer año $(0,4 \mathrm{~mm})$ menor a la observada en sistemas con conexión externa (25). Además en casos de implantes con una conexión externa, en donde existiría un microgap mayor, se ha observado que si se coloca el cuello del implante de manera supracrestal , la reabsorción no es de 1,5 mm como en la colocación habitual, sino solo de 0,5 (26). Se desconoce, sin embargo si la menor reabsorción ósea observada en estos estudios se debe a la localización y anchura de la interfase pilar-implante o la mejor distribución biomecánica al hueso. En cualquier caso las repercusiones clínicas de la invasión bacteriana del microgap son todavía desconocidas.

\section{3-REACCIÓN A CARGAS BIOMECÁNICAS}

La influencia de cargas axiales o no axiales excesivas o patológicas (se considera que por encima de $4000 \mu \varepsilon$, que se corresponde a una deformación celular del $0,4 \%$ ) sobre esa zona crestal, produciría una fractura por fatiga de la interfase hueso-implante y del hueso adyacente. Parece que se produciría un aumento del remodelado con mayor fase reabsortiva, al igual que ocurre con el "desuso" (14). Se establece que estas sobrecargas patológicas no son las causantes de la perdida localizada "en embudo" de la zona crestal cervical, ya que en condiciones de esa sobrecarga patológica no se perdería la unión únicamente en la zona crestal sino a todo lo largo del implante de manera rápida, o bien se produciría la fractura de la fijación (27). Se ha comprobado mediante simulación de elementos finitos que la calidad del hueso tiene mayor relevancia para la distribución del estrés, y por consiguiente de la producción de microdeformaciones $(\mu \varepsilon)$, que la altura crestal. Cuando el hueso se simula muy poroso y sin presencia de cortical, al aplicar una carga axial de $150 \mathrm{~N}$, la distribución de deformaciones se distribuye de manera homogénea a lo largo del implante con cifras superiores a 4000 me. Cuando existe una zona cortical esas cifras elevadas solo se consiguen en la zona cervical del implante, mientras que en el resto del cuerpo se encuentran en rangos de sobrecarga media (1500-4000 $\mu \varepsilon)$ (28).

Se ha establecido también experimentalmente, que la sobrecarga biomecánica es un factor mas importante para la reabsorción ósea que la infección bacteriana. Isidor y cols (29)realizaron un estudio en mandíbula de monos donde se evidenció que implantes sometidos a una sobrecarga con una buena higiene perimplantaria, presentaron una pérdida de la osteointegración, mientras que los casos que tenían mala higiene sin sobrecarga, no la perdían. La perdida de osteointegración se achacó a "microfracturas por fatiga en el hueso que sobrepasaban el potencial reparador".

Mediante estudios de elementos finitos y de fotoelasticidad, se ha visto que la mayor transmisión y concentración de fuerzas se realiza en la región cervical y apical del implante. Parece que la macrogeometría del implante podría mejorar la disipación de estas fuerzas aunque esto no está bien definido.

Con el fín de reducir la transmisión de fuerzas de compresión al hueso adyacente de la zona coronal, se están investigando diseños en los que se añade a la zona cervical del implante un anillo de $0,1 \mathrm{~mm}$ de espesor a base de HA-polietileno que serviría como rompefuerzas a ese nivel. Mediante medición de elementos finitos en 3D se ha observado distribución de este nuevo diseño al hueso de $9,8 \mathrm{MPa}$ ante carga vertical, y de 89,5 $\mathrm{MPa}$ ante carga horizontal, frente a la distribución 12,1 $\mathrm{MPa}$ y 134,6 MPa en los implantes sin anillo (30).

Siguiendo una hipótesis del "desuso" en el hueso crestal, se establecería que incluso sin cargas patológicas, en el caso de diseños con cuello pulido, en esa zona no existiría una suficiente unión hueso implante para distribuir las fuerzas, lo que originaría un fenómeno de desuso de esa zona induciendo una reabsorción 


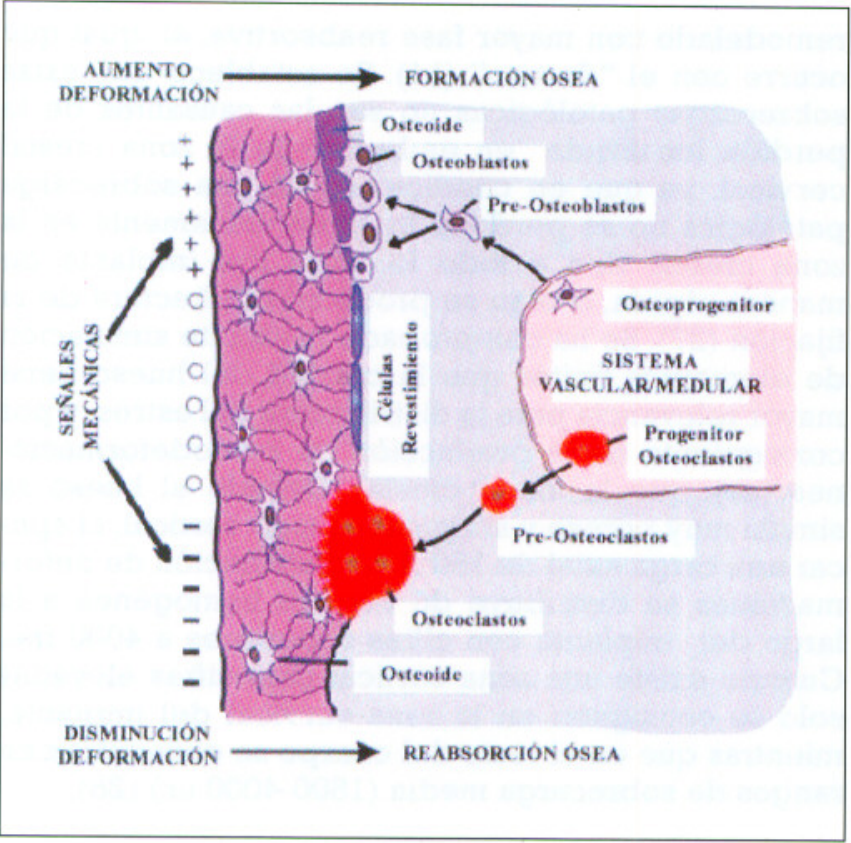

Fig. 3: Activación celular según la aplicación de cargas biomecánicas. Modificado de Roach (35).

por modelado catabólico o remodelado con aumento de fase de reabsorción. (por debajo de $100 \mu \varepsilon$ ) (Figuras 3 y 4). Esta hipótesis justificaría los casos de perdida rápidamente progresiva en los implantes impactados una vez que se someten a carga.

Jung y cols (31), realizan un estudio clínico midiendo radiográficamente la pérdida ósea crestal, en implantes con diferentes anchuras del cuello pulido entre 1 y $4,5 \mathrm{~mm}$, observando una correlación entre la mayor anchura del cuello y mayor reabsorción ósea. Observaron que más del $50 \%$ de la pérdida ósea ocurría en los primeros 3 meses.

Con el objetivo de conseguir mayor unión y transmitir las cargas de manera más favorable al hueso en esa zona cervical, hay diseños que no tienen el cuello pulido sino que inician directamente su superficie roscada en la cabeza del implante (P.Ej ST, AstraTech). Otros diseños tampoco tienen el cuello pulido, sino que en esa zona siguen teniendo la zona rugosa aunque sin espiras (P.Ej MK IV, TiUnite, Nobelbiocare).

Mediante estudio de elementos finitos, se ha visto que un diseño de rosca más pequeño de lo habitual en la zona cervical, permitiría asimilar mayores cargas axiales, mejoraría la distribución de la carga de manera axial a lo largo del implante y disminuiría mejor el estrés de cizallamiento que los diseños con cuello pulido (32). Utilizando este macrodiseño (ST, Astra-Tech) Nordin realiza un seguimiento de 1 año colocando 25 implantes y con prótesis parciales fijas

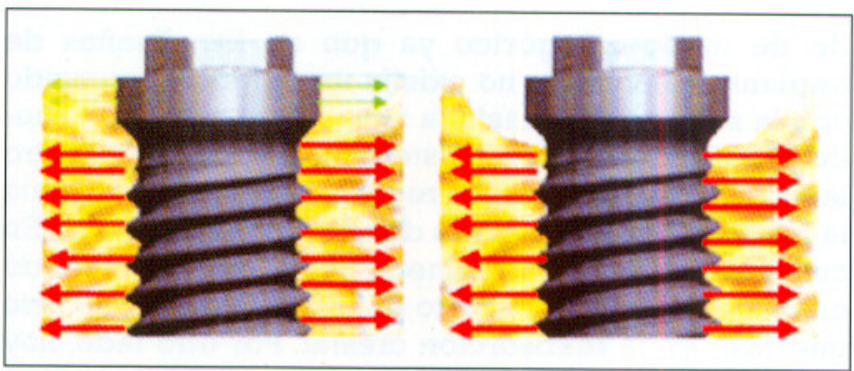

Fig. 4: Hipótesis del desuso en la reabsorción crestal.

implantosoportadas, observando una pérdida media de hueso marginal de $0,05 \mathrm{~mm}$, con una tasa de exito del $100 \%$ (33). Norton (8) realiza un seguimiento clínico en 33 implantes (ST, Astra-Tech) unitarios observando las siguientes medias acumulativas de perdida ósea crestal en mesial: a los 0,5-1 año (33 implantes) 0,32 mm; a 1-2 años (25 implantes) 0,42; a 2-3 años (16 implantes) 0,54 mm; a 3-4 años (10 implantes) 0,51 mm; a 4-5 años (4 implantes) 0,62 mm. La desventaja de este diseño se podría plantear cuando la zona rugosa es expuesta al medio oral por causa bacteriana. Norton, sin embargo, refiere uno de los casos que presentó una reabsorción de la cresta con comunicación de la zona roscada con el medio oral y que no presentó ningún tipo de inflamación. El autor también atribuye la menor pérdida de hueso crestal a la conexión cónica implante-pilar que mejoraría la distribución de las cargas al cuerpo del implante.

Existen diversos diseños del perfil de rosca en cuanto a forma e inclinación con la finalidad de mejorar la transmisión de las fuerzas al hueso. Se considera, cualquiera que sea la carga, que la distribución del estrés en las roscas es heterogéneo, de tal manera que la máxima concentración de las cargas se producen en la parte exterior de la rosca y disminuye hacia la región interior de la rosca. La forma de la rosca va a afectar la distribución del estrés, siendo mas favorables los perfiles redondeados que los perfiles afilados (27).

Se han diseñado pasos de rosca discontinuos que teóricamente permitirían una mayor penetración del hueso con mejores propiedades biomecánicas (entrada completa de una osteona secundaria) entre las roscas, que los pasos de rosca continuos clásicos en 60 (Figura 5). Esto no está demostrado ni experimental ni clínicamente. Por otro lado hay que pensar que no hay ningún diseño de implante en el que se obtuviera in vivo una unión hueso-implante del $100 \%$, considerándose de manera teórica un porcentaje de $35 \%$ de unión hueso-implante (BIC) adecuado para resistir las cargas (34). En cualquier caso, la falta de unión al hueso en determinadas zonas del implante se debe considerar más como un fenómeno "discontinuo" más que "incompleto", considerando la osteointegración más como un proceso que 


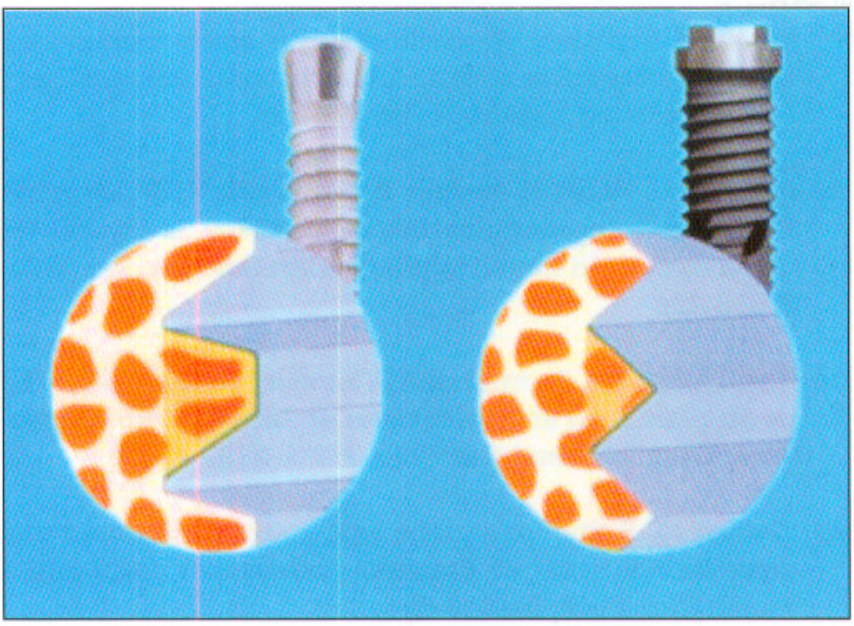

Fig. 5: Pasos de rosca continuos y discontinuo.

no un resultado, ya que el remodelado y modelado de esa interfase puede durar hasta 3 años.

Los pasos de rosca continuos en 60 grados tienen una anchura entre picos de $600 \mathrm{~mm}$ los que impediría en el interior de los valles la entrada de una osteona completa. Los pasos de rosca discontinuos permitirían un mejor crecimiento del hueso con la penetración de la osteona secundaria completa con unas propiedades biomecánicas mejores. Sin embargo, la existencia de menos roscas en este diseño discontinuo por superficie del implante, tendría un peor resultado a la hora de distribuir el estrés biomecánico al hueso adyacente y además existiría menor posibilidad de estabilidad primaria.

\section{ABSTRACT}

Dental implant design is frequently changing by scientific and comercial reasons. We realised a review about how clinical and biological aspects of macrogeometry affect at mucous and bone interface.

The results of articles revised showed that new implant designs improved the primary stability in bone with low density and are better to distribute biomechanical loads. Some designs permit implant placement in defects of alveolar anatomy and in postextraction sockets.The experimental and clinical results proved that designs without smooth neck, conic form, self-tapping apex, those with a double or three espiral and round profile threads.

\section{KEY WORDS}

Design, macrogeometry, implant

\section{CORRESPONDENCIA}

\author{
José M Martínez-González \\ Departamento Medicina y Cirugía Bucofacial \\ Facultad de Odontología. UCM. \\ Av. Complutense s/n. 28040 Madrid
}

\section{BIBLIOGRAFÍA}

1. Block MS, Gardiner D, Kent JN, Misiek DJ , Finger IM, Guerra L. Hydroxiapatite-coated cylindrical implants in the posterior mandible: 10-year observations. Int J Oral Maxillofac Imp 1996; 11:626-633.

2. Kapur KK. Veterans administration cooperative dental implant study-comparisons between fixed partial dentures supported by blade vent implants and removable part dentures.Part II.Comparisions of success rates and periodontal health between two treatments modalities. J Prosth Dent 1989; 62: 685-703.

3. Tonetti MS. Determination of the suces and failure of rootform osseointegrated dental implants. Adv Dent Res 1999; 13: 173-180.

4. Deporter D, Pilliar RM, Todescan R, Watson P, Pharoah M. Managing the posterior mandible of partially edentulous patients with short, porous-surfaced dental implants: Early data from a clinical trial. Int J Oral Maxillofac Imp 2001; 16: 653-658.

5. Friberg B, Sennerby L, Meredith N. A comparison between cutting torque and resonance frequency measurements of maxillary implants. A 20 month clinical study. Int J Oral Maxillofac Surg 2001; 28: 297-303.

6. Meredith N.Implant stabilty,function and clinical success. En: European comission demostration project. Resonance frequency analysis symposium. 2000. Gothenburg, Sweden: 2-6.

7. Martínez H, Davarpanah M, Missika P, Celletti R, Lazzara R. Optimal implant stabilization in low density bone. Clin Oral Impl Res 2001; 12: 423-432.

8. Norton M.Marginal bone levels at single tooth implants with a conical fixture design. The influence of surface macro and microestucture. Clin Oral Impl Res 1998; 9: 91-99.

9. O'Sullivan D, Sennerby L, Meredith N. Measurements comparing the initial stability of five designs of dental implants: A human cadáver study. Clin Impl Dent Rel Res 2000; 2 (2): 85-92.

10. Payne AG, Tawse-Smith A, Kumara R, Thomson WM. Oneyear prospective evaluation of the early loading of uns- 


\section{AVANCES}

Volumen 14 - No 3 - Octubre 2002

plinted conical branemark fixtures with mandibular overdentures immediately following surgery. Clin Impl Dent Rel Res 2001;3(1): 9-19.

11. Clemens JAM, Klein CPAT, Sakkers RJB, Dhert WJA, De Groot K, Rozing PM. Healing of gaps around calcium phosphate-coated implants in trabecular bone of the goat. J Biomed Mater Res 1997;36: 55-64.

12. Wheeler SL, Vogel RE, Casellini R. Tissue preservation and maintenance of optimum esthetics: $\mathrm{A}$ clinical report. Int J Oral Maxillofac Imp 2000; 15: 265-271.

13. Schultes G, Gaggl A. Histologic evaluation of immediate versus delayed placement of implants after tooth extraction. Oral Surg Oral Med Oral Pathol Oral Radiol Endod 2001; 92: 17-22.

14. Brunski JB, Puleo D, Nancy A. Biomaterials and biomechanics of oral and maxillofacial implants: currents status and future developments. Int J Oral Maxillofac Impl 2000; 15 (1): 15-46.

15. Tarnow DP, Cho SC,Wallace SS. The effect of interimplant distance on the height of inter-implant bone crest. J Periodontol 2000; 71: 546-549.

16. Albrektsson T, Zarb G, Worthington P. The long-term efficacy of currently used dental implants: a review and proposed criteria of success. Int J Oral Maxillofac Imp 1986; 1: 11-25.

17. Tal H, Moses O, Nemcovsky CE, Kozlovsky A. Spontaneous early exposure of submerged endosseous implants resulting in crestal bone loss: A clinical evaluation between stage I and stage II surgery. Int J Oral Maxillofac Imp 2001; 16: 514-521.

18. Bollen CML, Papaioannou W, Van Eldere J, Schepers C, Quirynen M, Van Steenberghe D. the influence of abutment surface roughness on plaque accumulation and periimplant mucositis. Clin Oral Imp Res. 1996; 7:201-211.

19. Sánchez A, Bermejo A. Revisión de los constituyentes implantológicos en función de sus relaciones tisulares. Quintessence 2001. 14: 68-75

20. Hermann JS, Cochran DL, Nummikoski PV, Buser D. Crestal bone changes around titanium implants. A radiographic evaluation of unloaded nonsubmerged and submerged implants in the canine mandible. J Periodontol 1997; 68 (11): 1117-1130.

21. O'Mahony A, MacNeill SR, Cobb CM. Rasgos del diseño que pueden influir en la retención de placa bacteriana. Análisis retrospectivo de implantes fracasados. Quintessence 2000. 14 (1):27-35.

22. Hermann JS, Schoolfield JD, Nummikoski PV, Buser D, Schenk RK, Cochran DL. Crestal bone changes around titanium implants: $\AA$ methodologic study comparing linear radiographic with histometric measurements. Int J Oral maxillofac Impl 2001; 16: 475-485.

23. Brägger U, Häfeli U, Hurber B, Hämmerle CHF, Lang NP. Evaluation of postsurgical crestal bone levels adjacent to non-submerged dental implants. Clin Oral Imp Res 1998; 9: $218-224$

24. Abrahamsson I, Berglundh T, Wennström J, Lindhe J. The perimplant hard and soft tissues at different implant systems. Clin Oral Impl Res 1996. 7:212-219.

25. Cooper LF. A role for surface topography in creating and maintaining bone at titanium endosseous implants. J Prosth Dent 2000; 84: 522-534.

26. Davarpanah M, Martinez H, Tecucianu JF. Apical-coronal implant position: recent surgical proposala. Technical note. Int J Oral Maxillofac Imp 2000; 15 (6); 865-872.

27. Wiskott HWA, Belser UC. Lack of integration of smooth titanium surfaces: a working hypothesis based on strains generated in the surrounding bone. Clin Oral Impl Res 1999; 10: 429-444.

28. Meyer U, Vollmer D, Runte C, Bourauel C, Joos U. Bone loading pattern around implants in average and atrophic edentulous maxillae: a finite-element analysis. J Craniomaxillofac Surg 2001; 29: 100-105.

29. Isidor F. Loss of osseointegration caused by oclusal load of oral implants. Clin Oral Implants Res 1996; 7: 143-152. on the integration of titanium implants. A study in rabbit tibia.In J Oral Maxillofac Surg 1996; 25: 229-235.

30. Abu-Hammad OA, Harrison A, Williams D. The effect of hydroxyapatite stress distributor in a dental implant on compressive stress levels in surronding bone. Int J Oral Maxillofac Imp 2000; 15: 559-564.

31. Jung $\mathrm{YC}, \mathrm{Han} \mathrm{CH}$, Lee $\mathrm{CH}$. A 1 year radiographic evaluation of marginal bone around dental implants. Int J Oral Maxillofac Impl 1996; 11:811-818.

32. Hansson S. The implant neck: smooth or provided with retention elements: A biomechanical approach. Clin Oral Impl Res 1999; 10: 394-405.

33. Nordin T, Jönsson G, Nelvig P, Rasmusson L. The use of a conical fixture design for fixed partial prosthese. A preliminary report. Clin Oral Impl Res 1998; 9: 343-347.

34. Kasemo B. Biocompatibility of titanium implants: surface science aspects. J Prosthet Dent 1983; 49: 832-837.

35. Roach HI. Bone anatomy and cell biology. http://www.ectsoc.org/reviews/011_roac.htm 